\title{
Corrigendum: The Arts of Coexistence: A View From Anthropology
}

\author{
Sara Asu Schroer* \\ Department of Culture Studies and Oriental Languages, Faculty of Humanities, University of Oslo, Oslo, Norway
}

\section{OPEN ACCESS}

Edited and reviewed by: Simon Pooley,

Birkbeck, University of London, United Kingdom

*Correspondence: Sara Asu Schroe s.a.schroer@ikos.uio.no

Specialty section: This article was submitted to

Human-Wildlife Dynamics,

a section of the journal

Frontiers in Conservation Science

Received: 09 December 2021 Accepted: 10 December 2021

Published: 05 January 2022

Citation:

Schroer SA (2022) Corrigendum: The Arts of Coexistence: A View From Anthropology.

Front. Conserv. Sci. 2:832236. doi: $10.3389 /$ fcosc.2021.832236
Keywords: anthropology, conservation, coexistence, relationally, more-than-human ethnography

\section{A Corrigendum on}

The Arts of Coexistence: A View From Anthropology

by Schroer, S. A. (2021). Front. Conserv. Sci. 2:711019. doi: 10.3389/fcosc.2021.711019

In the original article the following footnote is missing from the end of the first sentence: The title 'Arts of Coexistence' derives from a collaboratively organized workshop of the Oslo School of Environmental Humanities and the EASA network Humans and Other Living Beings, organized together with Ursula Münster and Hugo Reinert at the University of Oslo in May 2019.

The author apologizes for this error and states that this does not change the scientific conclusions of the article in any way. The original article has been updated.

Publisher's Note: All claims expressed in this article are solely those of the authors and do not necessarily represent those of their affiliated organizations, or those of the publisher, the editors and the reviewers. Any product that may be evaluated in this article, or claim that may be made by its manufacturer, is not guaranteed or endorsed by the publisher.

Copyright (๑) 2022 Schroer. This is an open-access article distributed under the terms of the Creative Commons Attribution License (CC BY). The use, distribution or reproduction in other forums is permitted, provided the original author(s) and the copyright owner(s) are credited and that the original publication in this journal is cited, in accordance with accepted academic practice. No use, distribution or reproduction is permitted which does not comply with these terms. 